\title{
The influence of dietary chestnut and quebracho tannins mix on rabbit meat quality
}

\author{
Simone Mancini ${ }^{1}$ (D) | Sara Minieri ${ }^{1,2}$ | Arianna Buccioni $^{3}$ | \\ Margherita Marzoni Fecia di Cossato $^{1,2}$ | Claudia Russo ${ }^{1,2}$ | Gisella Paci ${ }^{1,2}$
}

\author{
${ }^{1}$ Department of Veterinary Science, \\ University of Pisa, Pisa, Italy \\ ${ }^{2}$ Interdepartmental Research Center \\ "Nutraceuticals and Food for Health", \\ University of Pisa, Pisa, Italy \\ ${ }^{3}$ Department of Agri-Food Production and \\ Environmental Sciences (DISPAA), \\ University of Florence, Firenze, Italy

\section{Correspondence} \\ Simone Mancini, Department of Veterinary \\ Science, University of Pisa, Pisa, Italy. \\ Email:simafo@gmail.com; \\ simone.mancini@for.unipi.it
}

\begin{abstract}
Tannins were recently evaluated as feed additives in order to increase antioxidant compounds in animal diet, mainly to enhance resistance to lipid oxidation in meat. Rabbit meat is one of the most susceptible animal products, thus the main aim of this study was to evaluate the capacity of tannins to elongate shelf life of rabbit meat. Ninety hybrid rabbits were fed with three different diets: basal diet (control, C) and basal diet supplemented with $0.3 \%$ or $0.6 \%$ of tannins mix. Meat samples were refrigerated as raw at $4^{\circ} \mathrm{C}$ up to 11 days and analysed both as raw and cooked for physical-chemical characteristics, fatty acids profile, lipid oxidation and antioxidant capacity. Results showed that dietary tannins affected meat colour of raw samples (mostly yellowness). Lipid peroxidation (TBARS) of raw samples was lower in tannins group than C group; a further inhibition of peroxidation was showed also in cooked samples only by the highest dose of tannins mix. Moreover, antioxidant capacity (ABTS) of raw samples increased with the percentage of tannins. In conclusion, supplementation with $0.6 \%$ of tannins mix seems to positively affect the lipid peroxidation and antioxidant capacity of meat without modifying the intrinsic characteristics of rabbit meat.
\end{abstract}

\section{KEYWORDS}

antioxidant capacity, chestnut, quebracho, rabbit, tannins

\section{1 | INTRODUCTION}

Rabbit meat is mostly consumed in Europe (mainly in Italy, Spain and France), in Central America (Mexico) and in Asia (China and Democratic People's Republic of Korea) (FAO, 2018). Rabbit meat is excellent for both dietetic and nutritive purposes due to a low amount of lipids and high level of essential amino acids and polyunsaturated fatty acids, which are susceptible to lipid peroxidation (Petracci \& Cavani, 2013). During the last years, in order to reduce lipid oxidation, several researchers employed natural antioxidant both in diet (Dal Bosco et al., 2015; Mattioli et al., 2017) and in product processing (Mancini et al., 2017, 2017). Among plant products tannins exhibited strong antioxidant activity and their application was studied as food and feed additive (Chung, Wong, Wei, Huang, \& Lin, 1998).
Tannins are a complex group of water-soluble polyphenolic compounds, they are produced by plants as defence against external attacks. Tannins are classified as hydrolysable and non-hydrolysable (condensed) which differ in chemical structure (polymerization of gallic acid or flavone) as well as in chemical and biological characteristics. Normally, condensed and hydrolysable tannins are more reliable in tropical and temperate woods, respectively. In animal diet the most used tannins of the two distinct types are derived from chestnut (Castanea sativa Mill.) and quebracho (Schinopsis spp.) woods.

Different trials studied tannins for their physiological effects like antimicrobial, antiparasitic, antioxidant and antiradical activity (Marín-Martinez et al., 2009). Only few studies were conducted to evaluate the effect of the dietary tannins supplementation on meat quality. 
Dietary inclusion of chestnut tannins in pig showed to reduced lipid oxidation (Ranucci et al., 2015) as well to decrease malondialdehyde concentration in meat, serum and liver of heat-stressed lambs (Liu, Li, Mingbin, Zhao, \& Xiong, 2016). Quebracho tannins showed to affect colour stability during refrigerated storage of sheep meat even if no appreciable effect on lipid peroxidation was showed (Luciano et al., 2009). Few articles aimed to study the effects of chestnut or quebracho tannins as dietary supplementation on rabbit meat quality (Dalle Zotte \& Cossu, 2009; Gai et al., 2009; Liu, Dong, Tong, \& Zhang, 2011; Liu, Zhou, Tong, \& Vaddella, 2012; Liu et al., 2009). Furthermore, these researches, conducted on several animals, aimed to study the effect of a single type of tannin and few data are available on the effect of a mix of these two types of tannins (Mancini, Moruzzo, et al., 2018; Parisi et al., 2018).

For these reasons the aim of our study was to evaluate the effects on rabbit meat characteristics of two dietary doses of chestnut and quebracho tannins mix with the main focus on lipid oxidation. Moreover, in order to quantify the effects of dietary tannins on shelf life during commercial selling and human consumption a refrigerate storage of 11 days and a cooking sections were also considered.

\section{2 | MATERIAL AND METHODS}

\subsection{Animals and sampling}

Ninety 30-day-old hybrid rabbits were randomly allotted into three distinct groups and housed in colony cages (three rabbits/ cage, $60 \times 40 \mathrm{~cm}$ ). The cages were made of galvanised wire net and equipped with feeders and automatic drinkers. As basal diet (control, C) was used a commercial pellet (Table 1). One group of 30 rabbits fed the $\mathrm{C}$ diet, the other two experimental groups fed the same pellet supplemented with an extract of chestnut (Castanea sativa Mill.) and quebracho (Schinopsis spp.) tannins manufactured by Silvateam NUTRI P powder ${ }^{\circledR}$ (Ledoga S.r.l., Cuneo, Italy). Chemical composition of the tannin mix was: $750 \mathrm{~g} / \mathrm{kg}$ tannins, $150 \mathrm{~g} / \mathrm{kg}$ nontannin, $80 \mathrm{~g} /$ $\mathrm{kg}$ water and $20 \mathrm{~g} / \mathrm{kg}$ insolubles ( $\mathrm{pH} 4,0.1 \mathrm{mg} / \mathrm{ml}$ solution) on a fresh matter basis. The total tannin content was determined according to ISO 14088:2012 (2012).

Tannins mix was added at the concentrations of $0.3 \%$ (diet 0.3 ) or $0.6 \%$ (diet 0.6 ) of the feed $(0.34 \mathrm{~g} / 100 \mathrm{~g}$ and $0.68 \mathrm{~g} / 100 \mathrm{~g}$ of dry matter respectively). The two experimental concentrations were chosen on the basis of previous research studies on rabbit dietary supplementation with chestnut (Gai et al., 2009; Liu et al., 2009, 2011, 2012) and quebracho (Dalle Zotte \& Cossu, 2009) tannins used alone.

Rabbits were fed ad libitum as well water was freely available from nipple drinkers. The experimental protocol was designed according to the guidelines of the current European and Italian laws on the care and use of experimental animals (European directive 2010/63/UE, put into law in Italy with D. Lgs. 26/2014).

During the whole experimental period (60 days) body weights and feed intake were registered weekly as well as any subject death and morbidity episode.

Ten rabbits from each experimental group were slaughtered at 90 days of age ( 60 days of diet trial). Rabbits were electro-stunned and slaughtered by cutting carotid and jugular veins. The dissection procedures of warm and chilled carcasses followed the World Rabbit Science Association (WRSA) recommendations (Blasco \& Ouhayoun, 1996).

At 1 day post mortem, left and right Longissimus thoracis et lumborum muscles were dissected and used for meat quality assessments after being individually packaged in Styrofoam trays overwrapped with polyethylene film and stored at $4^{\circ} \mathrm{C}$ up for 10 days (namely 11 days post mortem; samples analysed after 2, 7 and 11 days post mortem - T2, T7 and T11). Right muscles were analysed as raw samples, left muscles were cooked at the time of analysis and tested as cooked samples.

Proximate composition was assessed as dry matter, protein and ether extract only on right muscles at T2 accordingly to the methods reported in AOAC (1995).
TABLE 1 Ingredients (\% as feed basis), proximate composition ( $\mathrm{g} / \mathrm{kg}$ as fed), digestible energy $(\mathrm{MJ} / \mathrm{kg})$ and fatty acid profile (\% total fatty acids) of control diet (C)

\begin{tabular}{|c|c|c|c|c|c|c|}
\hline \multicolumn{2}{|l|}{ Ingredients } & \multicolumn{3}{|c|}{ Chemical composition } & \multicolumn{2}{|c|}{ Fatty acids profile } \\
\hline Alfalfa meal & 40.0 & Dry matter & & 890 & C16:0 & 28.17 \\
\hline Wheat bran & 30.0 & Crude protein & & 157 & C18:0 & 4.99 \\
\hline Barley & 15.0 & Ether extract & & 43 & C2O:0 & 0.38 \\
\hline Sunflower meal & 9.0 & Ash & & 86 & SFA & 33.54 \\
\hline Soya oil & 1.5 & Crude fibre & & 154 & C18:1w9 & 47.34 \\
\hline Calcium Carbonate & 1.1 & & NDF & 340 & $C 20: 1 \omega 9$ & 0.84 \\
\hline Cane molasses & 1.1 & & ADF & 190 & MUFA & 48.18 \\
\hline Beet pulp & 1.1 & & $A D L$ & 46 & $\mathrm{C} 18: 2 \omega 6$ & 7.77 \\
\hline Salt & 0.7 & Digestible energy & & 9.79 & 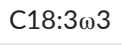 & 10.46 \\
\hline Premix $^{a}$ & 0.5 & & & & PUFA & 18.23 \\
\hline
\end{tabular}

aPremix provided per kg of diet: manganus sulphate monohydrate $138 \mathrm{mg}$; zinc sulphate monohydrate $205 \mathrm{mg}$; ferrous sulphate monohydrate $273 \mathrm{mg}$; copper sulphate pentahydrate $35 \mathrm{mg}$; potassium iodide 1.31 mg; iodine selenite 481 mg; vitamin A 10000 UI; vitamin D3 900 UI; vitamin E 30 mg. 
At T2, T7 and T11 raw and cooked samples were analysed for the determination of $\mathrm{pH}$, water holding capacity (drip loss and cooking loss), colour, fatty acids profile, lipid peroxidation and antioxidant capacity.

\section{2 | pH, water holding capacity and colour}

The $\mathrm{pH}$ was determined by a Eutech $\mathrm{pH}$ 2,700 Meter (Eutech Instruments Pte Ltd, Singapore) equipped with electrode suitable for meat penetration (2 Pore Slim, XS Sensor, Modena, Italy) and an automatic temperature compensator. $\mathrm{pH}$ was assessed in three different points for each sample and prior to each session the $\mathrm{pH}$ meter was calibrated with buffered solutions ( $\mathrm{pH} 4.01$ and 7.01).

Drip loss was calculated as the loss of weight between T2 and T7 or T2 and T11 of raw samples (Lundström \& Malmfors, 1985); cooking loss was quantified as loss of weight after cooking in a preheated oven at $163^{\circ} \mathrm{C}$ to an internal temperature of $71^{\circ} \mathrm{C}$ (AMSA, 1995).

Colour was determined through a Minolta CR300 chroma meter (Minolta, Osaka, Japan) with aperture size of $8 \mathrm{~mm}$, illuminant D65, incidence angle of $2^{\circ}$. CIELab parameters (CIE, 1976) were recorded in three different spots of each samples. Hue $\left(\mathrm{H}^{*}\right)$ and chroma $\left(C^{*}\right)$ indexes were calculated on $a^{*}$ and $b^{*}$ parameters (CIE, 1976). Chroma meter was calibrated before each session on a white plate $\left(L^{*}=98.14, a^{*}=-0.23\right.$ and $\left.b^{*}=1.89\right)$.

Colour differences between samples were calculated on the formula proposed by Sharma and Bala (2002) as numerical total colour difference as follows:

$$
\Delta \mathrm{E}_{\alpha-\beta}=\left[\left(\mathrm{L}_{\alpha}^{*}-\mathrm{L}_{\beta}^{*}\right)^{2}+\left(\mathrm{a}_{\alpha}^{*}-\mathrm{a}_{\beta}^{*}\right)^{2}+\left(\mathrm{b}_{\alpha}^{*}-\mathrm{b}_{\beta}^{*}\right)^{2}\right]^{0.5}
$$

where $L_{\alpha}^{*}, a^{*}{ }_{\alpha}, b^{*}{ }_{\alpha}$, and $L_{\beta}^{*}, a_{\beta}^{*}, b_{\beta}^{*}$ are the values of two different diets or two different storage times. A variation in colour $(\Delta \mathrm{E})$ equal to 2.3 units corresponds to a just-noticeable difference (JND) for the human eye; higher variation is considered discernible.

\subsection{Fatty acids profile}

Lipids were extracted from $5 \mathrm{~g}$ of minced muscle with chloroformmethanol $(2: 1 \mathrm{v} / \mathrm{v})$ according to the method of Folch, Lees, and Sloane-Stanley (1957).

The fatty acid methyl esters (FAMEs) were prepared with a base-catalysed transesterification according to Christie (1982). The FAMEs were separated on a gas-chromatograph equipped with a capillary column (CP-Select CB for FAMEs Varian, Middelburg, Netherlands: $100 \mathrm{~m}, 0.25 \mathrm{~mm}$ i.d., film thickness $0.20 \mathrm{~mm}$ ) and quantified using nonadecanoic acid (C19:0) methyl ester (Sigma Chemical Co., St. Louis, MO, USA) as internal standard. The injector and flame ionization detector temperatures were $270{ }^{\circ} \mathrm{C}$ and 300 ${ }^{\circ} \mathrm{C}$, respectively. The programmed temperature was $40^{\circ} \mathrm{C}$ for $4 \mathrm{~min}$, increased to $120^{\circ} \mathrm{C}$ at a rate of $10^{\circ} \mathrm{C} \mathrm{min}^{-1}$, maintained at $120^{\circ} \mathrm{C}$ for $1 \mathrm{~min}$, increased to $180^{\circ} \mathrm{C}$ at a rate of $5^{\circ} \mathrm{C} \mathrm{min}-1$, maintained at 180 ${ }^{\circ} \mathrm{C}$ for $18 \mathrm{~min}$, increased to $200^{\circ} \mathrm{C}$ at a rate of $2^{\circ} \mathrm{C} \mathrm{min}^{-1}$, maintained at $200{ }^{\circ} \mathrm{C}$ for $1 \mathrm{~min}$, increased to $230^{\circ} \mathrm{C}$ at a rate of $2{ }^{\circ} \mathrm{C} \mathrm{min}-1$ and maintained at this last temperature for $19 \mathrm{~min}$. The split ratio was 1:100 and helium was the carrier gas with a flux of $1 \mathrm{~mL} \mathrm{~min}{ }^{-1}$. Fatty acid (FA) composition of the samples was calculated and expressed as a percentage of the total FAs (\%).

The average amount of each FA was used to calculate the sum of the saturated (SFA), monounsaturated (MUFA) and polyunsaturated fatty acids (PUFA) and to calculate the atherogenicity index (AI), the thrombogenicity index ( $\mathrm{TI})$, the peroxidisability index (PI) and the ratio hypocholesterolemic - hypercholesterolemic indexes $(\mathrm{h} / \mathrm{H})$ as reported by Ulbricht and Southgate (1991) and Santos-Silva, Bessa, and Santos-Silva (2002):

$\mathrm{Al}=[\mathrm{C} 12: 0+(4 \times \mathrm{C} 14: 0)+\mathrm{C} 16: 0] /(\Sigma \mathrm{PUFA} \omega 3+\Sigma \mathrm{PUFA} \omega 6+\Sigma \mathrm{MUFA})$

$$
\begin{aligned}
\mathrm{TI}= & (\mathrm{C} 14: 0+\mathrm{C} 16: 0+\mathrm{C} 18: 0) /((0.5 \times \Sigma \text { MUFA })+(0.5 \times \Sigma \mathrm{PUFA} \omega 6) \\
& +(3 \times \Sigma \mathrm{PUFA} \omega 3)+(\Sigma \mathrm{PUFA} \omega 3 / \Sigma \mathrm{PUFA} \omega 6)]
\end{aligned}
$$

$$
\begin{aligned}
\mathrm{h} / \mathrm{H} & =(\mathrm{C} 18: 1 \omega 9+\mathrm{C} 18: 2 \omega 6+\mathrm{C} 20: 4 \omega 6+\mathrm{C} 18: 3 \omega 3 \\
& +\mathrm{C} 20: 5 \omega 3+\mathrm{C} 22: 5 \omega 3+\mathrm{C} 22: 6 \omega 3) /(\mathrm{C} 14: 0+\mathrm{C} 16: 0)
\end{aligned}
$$

$\mathrm{PI}: \sum$ monoenoic $* 0.025+\sum$ dienoic $* 1+\sum$ trienoic $* 2$

$$
+\sum \text { tetraenoic } * 4+\sum \text { pentaenoic } * 6+\sum \text { hexaecoic } * 8
$$

\subsection{Lipid peroxidation and antioxidant capacity}

Thiobarbituric acid reactive substances (TBARS) were evaluated using the procedure described by Leick et al. (2010). Absorbances of the samples were quantified with a spectrophotometer to wave length of $532 \mathrm{~nm}$ (V-530 Jasco International, Milan, Italy). A standard concentration curve of TEP (1,1,3,3-tetraethoxypropane; 0-7.5 mM) was plotted in order to obtain the sample's MDA concentration. Results were expressed as mg MDA/kg of sample.

Antioxidant capacity was assessed on ethanol extracted samples according to Mancini et al. (2015) with three different methods using the ABTS probe (ABTS reducing activity assay; ABTS, 2,20-az inobis(3-ethylbenzthiazoline-6-sulphonic acid)) as reported by $\operatorname{Re}$ et al. (1999), the DPPH probe (DPPH scavenging activity; DPPH, 2,2-diphenyl-1-picrylhydrazyl) following the method of Blois (1958) modified by Jung et al. (2010) and the ferric reducing ability (FRAP) as described by Descalzo et al. (2007).

\subsection{Statistical analysis}

Rabbit live performances (body weights on individual data, feed intake and feed conversion ratio on cage) were statistically analysed via oneway ANOVA. Data obtained from physical $(\mathrm{pH}$, water holding capacity and colour) and chemical (fatty acids profile, lipid peroxidation and antioxidant capacity) quantifications on raw and cooked samples were analysed separately by a two factorial ANOVA with repeated measurements in time. Diet $\mathrm{D}$ (C, 0.3 and 0.6) and storage time T (T2, T7 and T11) were analysed as fixed factors and the animal was set as random factor. Moreover, the interaction $\mathrm{D} \times \mathrm{T}$ was also tested. Chi square test was used to compare non-parametric data (morbidity and mortality). 
Significance level was set at $5 \%$ and the differences were assessed using Tukey's test. Data were reported as the mean of the fixed effects $D$ and $T$ and the variability was expressed as Root Mean Square Error (RMSE). Statistical analysis was performed with the R free statistical software (R Core Team, 2015).

\section{3 | RESULTS AND DISCUSSION}

\subsection{Live performances, morbidity and mortality}

No significant differences were found in average daily weight gain, feed intake, feed conversion ratio and final live weight (Table 2). Indeed, the rabbit fed with diets supplemented with tannins showed similar performance to those of rabbits fed with $C$ diet. In the past tannins were described as anti-nutritive substance and studied for their anti-nutritional effects which reduced the performance in growing animals (Mueller-Harvey, 2006; Smulikowska et al., 2001). In contrast several authors showed lack of differences, or even increased ones, on the performances of rabbit and other species fed with diets supplemented by tannins (Liu et al., 2009, 2011). Similar results were observed by Liu et al. (2009) in rabbits fed with chestnut tannins who hypothesized that the reason might be related to the small amount of tannins supplemented in the diet. Furthermore, at low concentration seems that tannins played a role as a protective factor of the intestinal mucosa and as a control of peristaltic activity in presence of digestive disorders. The lack of effect of dietary tannins was also highlighted by the no statistical differences showed for morbidity rate and mortality rate (Table 2 ).

\subsection{Proximate analysis, $\mathrm{pH}$, colour and water holding capacity}

No significant differences were observed in proximate compositions of muscles at T2 (moisture: $73.43 \% \pm 0.81$; protein: $21.70 \% \pm 0.49$; ether extract: $1.05 \% \pm 0.07$; data not shown).

TABLE 2 Growth performance, morbidity and mortality of rabbits

\begin{tabular}{|c|c|c|c|c|c|}
\hline & \multicolumn{3}{|c|}{ Diet (D) } & \multirow[b]{2}{*}{$p$ value } & \multirow[b]{2}{*}{ RMSE } \\
\hline & C & 0.3 & 0.6 & & \\
\hline Initial LW, g & 826 & 829 & 822 & 0.995 & 80.2 \\
\hline Final LW, g & 2785 & 2773 & 2804 & 0.945 & 229.6 \\
\hline ADG, g/rabbit d & 31.9 & 30.8 & 31.6 & 0.893 & 3.54 \\
\hline $\mathrm{FI}, \mathrm{g} / \mathrm{rabbit} \mathrm{d}$ & 89.8 & 92.9 & 89.8 & 0.361 & 4.95 \\
\hline FCR & 2.96 & 3.07 & 2.93 & 0.548 & 0.221 \\
\hline Morbidity (\%) & 20.0 & 16.7 & 16.7 & 0.859 & \\
\hline Mortality (\%) & 16.7 & 10.0 & 10.0 & 0.859 & \\
\hline
\end{tabular}

LW, live weight; ADG, average daily weight gain; FI, feed intake; FCR, feed conversion ratio ( $\mathrm{kg}$ feed intake/ $\mathrm{kg}$ of live weight gain).

Diets: $\mathrm{C}$ - basal diet, control; 0.3 - basal diet $+0.3 \%$ of tannins blend; 0.6 - basal diet $+0.6 \%$ of tannins blend.
Effects of diet and storage time on $\mathrm{pH}$, water holding capacity and colour were reported in Table 3 . Inclusions of dietary tannins at both the concentrations affected the yellowness index of raw samples $(p<0.001)$, leading to a paler meat with a decrease of $C^{*}$ $(p<0.001)$. Results of other trials on dietary tannins supplementation in rabbit reported a large variability of colour modifications; Dalle Zotte and Cossu (2009) reported that rabbits fed quebracho's tannins showed higher $b^{*}$ value than control samples, on the other hand no modifications in colour parameters were reported in two different studies with chestnut tannins (Liu et al., 2009, 2012). In our trial, mix of quebracho and chestnut tannins seems to modify the samples colour in a different way from the two components used alone. No other modifications were highlighted on both raw and cooked samples on $\mathrm{pH}$ and colour indexes.

Storage time affected all the physical parameters (Table 3). As expected, $\mathrm{pH}$ and water holding capacity (both drip and cooking losses) increased during storage time $(p=0.043$ for $\mathrm{pH}$ and $p<0.001$ for both drip and cooking losses). The samples alkalinisation could be related to hydrolysis of proteins and to the degradation of amino acids (Karabagias, Badeka, \& Kontominas, 2011). Anyhow, even if raw samples showed an increase of $\mathrm{pH}$ during time, this modification did not appear in cooked ones ( $p>0.05)$.

The meat colour was affected by the storage time with an increase of $L^{*}, a^{*}$ and $b^{*}$. In particular in our study the T11 samples showed lighter and more coloured meat than T2 ones.

These results were similar to those observed by Dal Bosco et al. (2014) who studied the effect of natural antioxidant and storage time on meat quality and observed an increase of $\mathrm{L}^{*} \mathrm{a}^{*} \mathrm{~b}^{*}$ and $\mathrm{pH}$ during storage time. Similarly, Lo Fiego et al. (2004) reported that meat of rabbit fed vitamin $\mathrm{E}$ or vitamin $\mathrm{C}$ increased the lightness during storage time up to 8 days, as well as, Corino, Pastorelli, Pantaleo, Oriani, and Salvatori (1999) reported yellowness increasing during 11 days of storage in both control and dietary vitamin $\mathrm{E}$ supplemented animals.

Cooked samples showed a different trend of raw samples: both $L^{*}$ and $a^{*}$ showed to decrease during storage time. The lowest $L^{*}$ value in cooked samples at T11 could be related to the highest water losses occurred during cooking; as previously observed in rabbit meat products higher water losses affect negatively the increase of $\mathrm{L}^{*}$ naturally occurred during cooking (Mancini, Preziuso, \& Paci, 2016).

The colour differences $(\Delta \mathrm{E})$ of both raw and cooked samples were reported in Table 4. Raw samples of all the diets showed to modify their colour between T2 and T7 and maintain these differences at T11. Cooked samples showed a discernible $\Delta \mathrm{E}$ in the overall time (T2-T11); only the diet 0.3 showed a small variation also in the time between T2-T7 (near to the threshold of 2.3 points).

Colour variations as function of diet during the different storage times showed that at T2 there were no eye visible differences between diets; contrarily at T7 and T11 all the samples appeared different between each other. This variation could be related to the modification of $\mathrm{b}^{*}$ index by the dietary supplementation of tannins (as previously described, Table 3). 
TAB LE 3 Meat quality evaluations in function of the diet and storage time

\begin{tabular}{|c|c|c|c|c|c|c|c|c|c|c|}
\hline & \multicolumn{3}{|c|}{ Diet (D) } & \multicolumn{3}{|c|}{ Storage time $(T)$} & \multicolumn{3}{|l|}{$p$ value } & RMSE \\
\hline \multicolumn{11}{|l|}{ Raw samples } \\
\hline $\mathrm{pH}$ & 5.72 & 5.64 & 5.65 & $5.61^{y}$ & $5.70^{x}$ & $5.71^{x}$ & 0.149 & 0.043 & 0.728 & 0.089 \\
\hline Drip loss (\%) & 1.39 & 1.61 & 1.69 & $0.00^{z}$ & $1.88^{y}$ & $2.94^{x}$ & 0.651 & $<0.001$ & 0.573 & 0.443 \\
\hline Cooking loss (\%) & 23.13 & 24.35 & 24.45 & $19.66^{z}$ & $22.46^{y}$ & $29.80^{x}$ & 0.422 & $<0.001$ & 0.186 & 2.301 \\
\hline$a^{*}$ & 0.68 & 0.57 & 0.58 & $0.43^{y}$ & $0.63^{x}$ & $0.77^{x}$ & 0.201 & $<0.001$ & 0.058 & 0.130 \\
\hline$b^{*}$ & $2.71^{a}$ & $1.74^{\mathrm{b}}$ & $1.66^{b}$ & $0.82^{z}$ & $2.30^{y}$ & $3.00^{x}$ & $<0.001$ & $<0.001$ & 0.059 & 0.460 \\
\hline$C^{*}$ & $2.81^{\mathrm{a}}$ & $1.84^{b}$ & $1.78^{b}$ & $0.93^{z}$ & $2.39^{y}$ & $3.11^{x}$ & $<0.001$ & $<0.001$ & 0.074 & 0.439 \\
\hline $\mathrm{H}^{*}$ & 71.48 & 69.69 & 67.75 & $61.12^{y}$ & $72.56^{x}$ & $75.23^{x}$ & 0.499 & $<0.001$ & 0.642 & 6.576 \\
\hline$a^{*}$ & 1.78 & 1.50 & 1.34 & $2.17^{x}$ & $1.45^{y}$ & $1.02^{y}$ & 0.081 & $<0.001$ & 0.573 & 0.390 \\
\hline$b^{*}$ & 7.73 & 7.40 & 8.04 & 7.66 & 7.62 & 7.89 & 0.378 & 0.801 & 0.538 & 0.939 \\
\hline$C^{*}$ & 7.96 & 7.58 & 8.17 & 7.97 & 7.77 & 7.97 & 0.424 & 0.878 & 0.543 & 0.939 \\
\hline $\mathrm{H}^{*}$ & 76.87 & 78.53 & 80.47 & $74.17^{z}$ & $78.97^{y}$ & $82.73^{x}$ & 0.054 & $<0.001$ & 0.748 & 2.906 \\
\hline
\end{tabular}

Diets: $\mathrm{C}$ - basal diet, control; 0.3 - basal diet $+0.3 \%$ of tannins blend; 0.6 - basal diet $+0.6 \%$ of tannins blend.

$\mathrm{a}, \mathrm{b}, \mathrm{c}$ in the same row indicate significant differences for $\mathrm{D}$; ${ }^{\mathrm{x}, \mathrm{y}, \mathrm{z} \text { in }}$ the same row indicate significant differences for $\mathrm{T}$.

TAB LE 4 Total colour difference $(\Delta \mathrm{E})$ during storage time of the same diet and between different diets at the same storage time

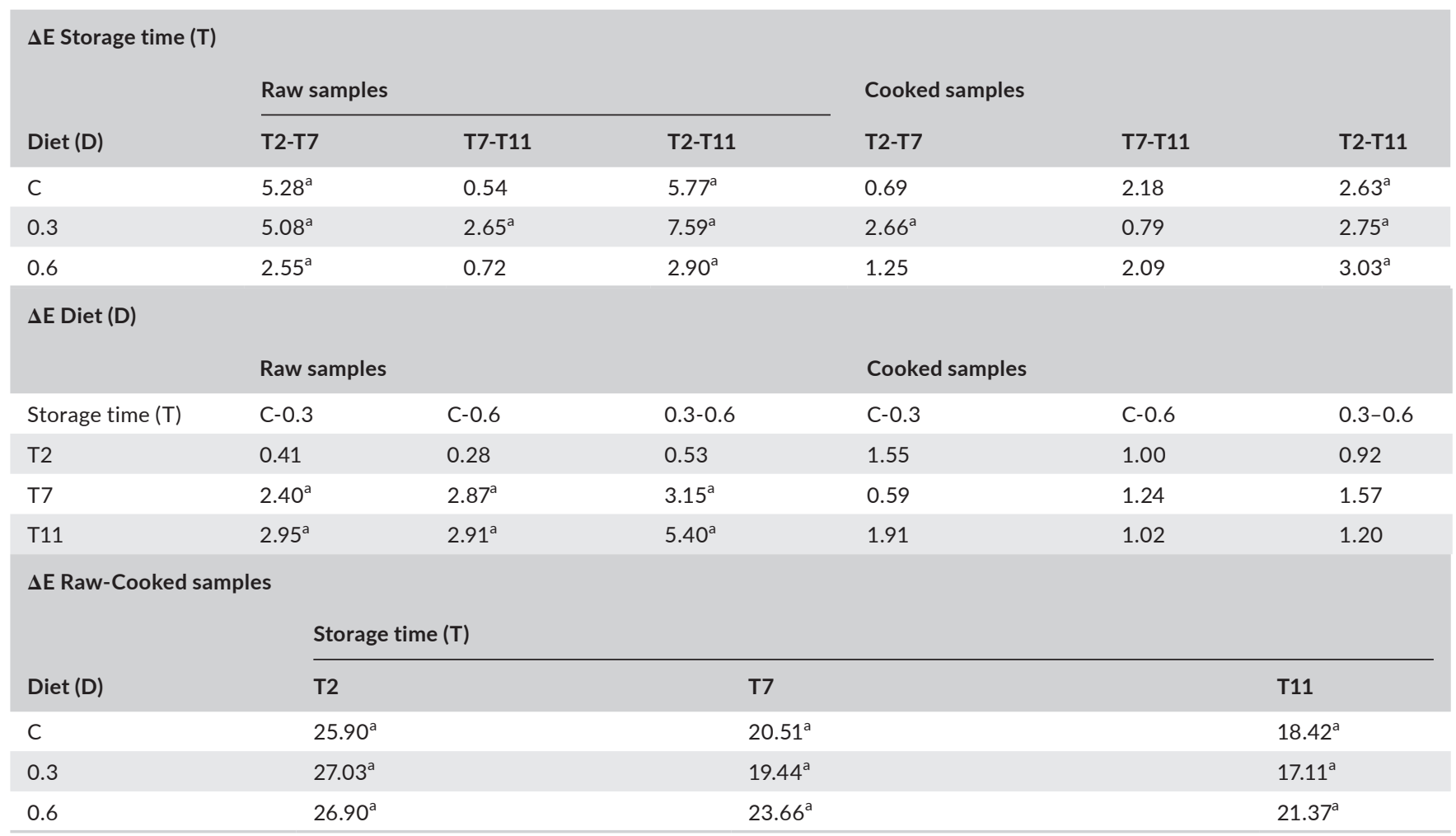

Diets: C - basal diet, control; 0.3 - basal diet $+0.3 \%$ of tannins blend; 0.6 - basal diet $+0.6 \%$ of tannins blend.

${ }^{a}$ Value over the threshold (2.3 points) with a noticeable difference in colour between the samples. 
TAB LE 5 Fatty acid compositions (\%) and calculated indexes of raw meat samples

\begin{tabular}{|c|c|c|c|c|c|c|c|c|c|c|}
\hline & \multicolumn{3}{|c|}{ Diet (D) } & \multicolumn{3}{|c|}{ Storage time $(\mathrm{T})$} & \multicolumn{3}{|l|}{$p$ value } & RMSE \\
\hline C14:0 & 1.45 & 1.45 & 1.47 & 1.47 & 1.47 & 1.43 & 0.578 & 0.071 & 0.864 & 0.035 \\
\hline C16:0 & 33.19 & 33.28 & 33.33 & 33.25 & 33.31 & 33.23 & 0.658 & 0.863 & 0.968 & 0.319 \\
\hline C18:0 & 10.31 & 10.22 & 10.55 & 10.40 & 10.36 & 10.32 & 0.152 & 0.878 & 0.999 & 0.359 \\
\hline $\mathrm{C} 24: 0$ & 1.43 & 1.47 & 1.45 & 1.46 & 1.46 & 1.43 & 0.103 & 0.074 & 0.918 & 0.032 \\
\hline C16:109 & 1.38 & 1.30 & 1.46 & 1.39 & 1.38 & 1.36 & 0.124 & 0.837 & 0.933 & 0.113 \\
\hline C18:109 & 27.84 & 27.63 & 27.76 & 27.80 & 27.74 & 27.70 & 0.108 & 0.601 & 0.556 & 0.201 \\
\hline MUFA & 31.55 & 31.21 & 31.63 & 31.53 & 31.48 & 31.39 & 0.111 & 0.316 & 0.436 & 0.394 \\
\hline 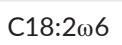 & 2.98 & 2.95 & 3.10 & $4.81^{x}$ & $2.50^{y}$ & $1.71^{z}$ & 0.405 & $<0.001$ & 0.622 & 0.248 \\
\hline PUFA $\omega 3$ & 2.87 & 2.77 & 2.80 & $3.95^{\mathrm{x}}$ & $2.82^{y}$ & $1.67^{z}$ & 0.583 & $<0.001$ & 0.700 & 0.210 \\
\hline PUFA & 15.40 & 15.23 & 15.26 & $18.29^{x}$ & $14.78^{y}$ & $12.82^{z}$ & 0.702 & $<0.001$ & 0.845 & 0.449 \\
\hline$\omega 3 / \omega 6$ & 0.22 & 0.22 & 0.22 & $0.27^{x}$ & $0.24^{y}$ & $0.15^{z}$ & 0.654 & $<0.001$ & 0.633 & 0.018 \\
\hline $\mathrm{Al}$ & 0.77 & 0.78 & 0.78 & $0.73^{z}$ & $0.78^{y}$ & $0.82^{x}$ & 0.072 & $<0.001$ & 0.542 & 0.009 \\
\hline $\mathrm{TI}$ & 1.47 & 1.50 & 1.50 & $1.29^{z}$ & $1.48^{y}$ & $1.70^{x}$ & 0.330 & $<0.001$ & 0.658 & 0.045 \\
\hline$h / H$ & 1.14 & 1.13 & 1.13 & $1.19^{x}$ & $1.12^{y}$ & $1.10^{z}$ & 0.259 & $<0.001$ & 0.540 & 0.014 \\
\hline PI & 46.31 & 45.97 & 45.51 & $50.21^{x}$ & $45.36^{y}$ & $42.22^{z}$ & 0.300 & $<0.001$ & 0.799 & 1.062 \\
\hline
\end{tabular}

Diets: C - basal diet, control; 0.3 - basal diet + 0.3\% of tannins blend; 0.6 - basal diet $+0.6 \%$ of tannins blend. The fatty acids C12:0, C15:0, C17:0,

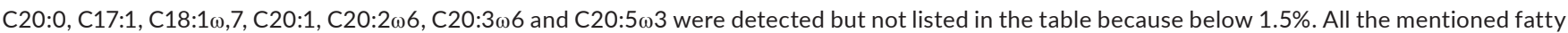
acids have been utilised for calculating the sums of the lipid fractions.

$\mathrm{x}, \mathrm{y}, \mathrm{z}$ in the same row indicate significant differences for $\mathrm{T}$.

Effect of cooking induced a colour variation to all the samples, with $\Delta$ Es ranged between 17.11 and 27.03. This modification leads to a uniformity of samples' colour, and as consequence, no colour differences were highlighted between cooked samples of different diets at the same storage time.

\section{3 | Fatty acid profile}

Effects of dietary supplementation of tannins mix and refrigerated storage on raw and cooked meat samples are reported in Table 5 and Table 6, respectively.

No dietary influences were highlighted in both the types of sample. These results could be expected as no variation in dietary fat composition was applied in this trial. Furthermore, no chemical mechanisms of action between tannins and fat were reported in literature, as on the contrary reported for the ability to precipitate alkaloids, gelatine and proteins (Van Buren \& Robinson, 1969).

Our results agreed with the findings of Dalle Zotte and Cossu (2009) that did not report modifications on FA profile in meat of rabbit fed $1 \%$ and $3 \%$ of quebracho tannins; similar results were reported as sums of SFA and PUFA by Liu et al. (2009) in dietary inclusion of $0.5 \%$ and $1.0 \%$ of chestnut tannins, even if were reported singular fatty acids modifications.
During storage time similar trends were showed by raw and cooked samples. As function of storage time linoleic acid and $\alpha$ linolenic acid decreased, these changes had a strong effect on the calculated sums of PUFA $\omega 6$, PUFA $\omega 3$ and total PUFA. Modifications in the concentrations of both $\omega 3$ and $\omega 6$ fatty acids affected the $\omega 3 /$ $\omega 6$ ratio, revealing an impoverishment of the meat characteristics. Indeed, calculated indexes confirmed that during storage time both raw and cooked samples worsened their health characteristics as $\mathrm{HH}$ and $\mathrm{PI}$ indexes raised and $\mathrm{Al}$ and $\mathrm{Tl}$ indexes decreased.

\subsection{Lipid peroxidation and antioxidant capacity}

Lipid peroxidation (TBARS) and antioxidant capacity (ABTS, DPPH and FRAP) of raw and cooked samples were reported in Table 7. FRAP method revealed a scarce ability of rabbit meat to react with reagents. This lack of sensitivity of FRAP method on dietary trial on rabbit meat was in part just highlighted in a previous research study conducted on the effect of dietary ginger powder on rabbit meat (Mancini, Secci, Preziuso, Parisi, \& Paci, 2018).

No significant interaction $D \times T$ was showed for TBARS, ABTS and DPPH. Dietary supplementation of tannins affected the lipid peroxidation of the raw samples, with lower values of TBARS of both 0.3 and 0.6 diets than $C$ diet. Moreover, an increased antioxidant capacity was revealed by ABTS method in raw samples, as rabbits 
TAB LE 6 Fatty acid compositions (\%) and calculated indexes of cooked meat samples

\begin{tabular}{|c|c|c|c|c|c|c|c|c|c|c|}
\hline & \multicolumn{3}{|c|}{ Diet (D) } & \multicolumn{3}{|c|}{ Storage time $(T)$} & \multicolumn{3}{|l|}{$p$ value } & RMSE \\
\hline C14:0 & 1.49 & 1.59 & 1.57 & 1.60 & 1.57 & 1.48 & 0.135 & 0.074 & 0.976 & 0.108 \\
\hline C16:0 & 32.02 & 32.09 & 32.32 & 32.10 & 32.14 & 32.18 & 0.234 & 0.896 & 0.934 & 0.371 \\
\hline C18:0 & 11.33 & 11.12 & 11.32 & 11.28 & 11.27 & 11.22 & 0.701 & 0.975 & 0.995 & 0.593 \\
\hline C24:0 & 2.33 & 2.16 & 2.38 & 2.30 & 2.28 & 2.29 & 0.352 & 0.993 & 0.991 & 0.327 \\
\hline C16:1 & 1.61 & 1.53 & 1.63 & 1.59 & 1.60 & 1.58 & 0.096 & 0.867 & 0.897 & 1.590 \\
\hline C18:1 & 27.26 & 27.63 & 27.43 & 27.42 & 27.36 & 27.54 & 0.199 & 0.644 & 0.610 & 0.418 \\
\hline MUFA & 31.18 & 31.47 & 31.44 & 31.32 & 31.25 & 31.52 & 0.341 & 0.442 & 0.837 & 0.444 \\
\hline 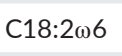 & 1.67 & 1.69 & 1.78 & $2.53^{x}$ & $1.37^{y}$ & $1.24^{z}$ & 0.300 & $<0.001$ & 0.722 & 0.160 \\
\hline PUFA $\omega 3$ & 1.92 & 1.79 & 1.82 & $2.65^{x}$ & $1.52^{y}$ & $1.36^{y}$ & 0.295 & $<0.001$ & 0.997 & 0.186 \\
\hline PUFA & 12.83 & 12.67 & 12.69 & $14.39^{x}$ & $12.06^{y}$ & $11.74^{y}$ & 0.580 & $<0.001$ & 0.931 & 0.364 \\
\hline$\omega 3 / \omega 6$ & 0.17 & 0.16 & 0.17 & $0.23^{x}$ & $0.14^{y}$ & $0.13^{y}$ & 0.233 & $<0.001$ & 0.953 & 0.015 \\
\hline Al & 0.86 & 0.87 & 0.88 & $0.89^{y}$ & $0.88^{x}$ & $0.84^{x}$ & 0.208 & $<0.001$ & 0.913 & 0.014 \\
\hline TI & 1.67 & 1.69 & 1.70 & $1.51^{y}$ & $1.76^{x}$ & $1.78^{x}$ & 0.598 & $<0.001$ & 0.992 & 0.053 \\
\hline$h / H$ & 1.17 & 1.17 & 1.16 & $1.21^{x}$ & $1.14^{y}$ & $1.14^{y}$ & 0.259 & $<0.001$ & 0.647 & 0.017 \\
\hline PI & 41.70 & 41.42 & 41.17 & $43.98^{x}$ & $40.42^{y}$ & $39.90^{y}$ & 0.581 & $<0.001$ & 0.956 & 1.065 \\
\hline
\end{tabular}

Diets: C - basal diet, control; 0.3 - basal diet $+0.3 \%$ of tannins blend; 0.6 - basal diet $+0.6 \%$ of tannins blend. The fatty acids C12:0, C15:0, C17:0, C20:0, C17:1, C18:1 $\omega, 7, C 20: 1, C 20: 2 \omega 6, C 20: 3 \omega 6$ and C20:5 $\omega 3$ were detected but not listed in the table because below $1.5 \%$. All the mentioned fatty acids have been utilised for calculating the sums of the lipid fractions.

$x, y, z$ in the same row indicate significant differences for $T$.

TAB LE 7 Lipid peroxidation (TBARS) and antioxidant capacity of raw and cooked meat samples (ABTS, DPPH and FRAP)

\begin{tabular}{|c|c|c|c|c|c|c|c|c|c|c|}
\hline & \multicolumn{3}{|c|}{ Diet (D) } & \multicolumn{3}{|c|}{ Storage time $(T)$} & \multicolumn{3}{|c|}{$p$ value } & RMSE \\
\hline \multicolumn{11}{|c|}{ Raw samples } \\
\hline TBARS & $0.13^{a}$ & $0.10^{b}$ & $0.09^{b}$ & $0.06^{y}$ & $0.12^{x}$ & $0.14^{x}$ & 0.006 & $<0.001$ & 0.073 & 0.023 \\
\hline ABTS & $0.85^{b}$ & $1.02^{\mathrm{ab}}$ & $1.09^{a}$ & $1.51^{x}$ & $0.84^{y}$ & $0.60^{z}$ & 0.016 & $<0.001$ & 0.334 & 0.161 \\
\hline \multicolumn{11}{|c|}{ Cooked samples } \\
\hline TBARS & $0.44^{a}$ & $0.43^{a}$ & $0.28^{b}$ & $0.19^{z}$ & $0.40^{y}$ & $0.56^{x}$ & 0.042 & $<0.001$ & 0.709 & 0.134 \\
\hline ABTS & 0.87 & 0.86 & 0.91 & $1.44^{x}$ & $0.89^{y}$ & $0.32^{z}$ & 0.506 & $<0.001$ & 0.210 & 0.087 \\
\hline DPPH & 0.03 & 0.03 & 0.03 & $0.05^{x}$ & $0.02^{y}$ & $0.02^{y}$ & 0.357 & $<0.001$ & 0.505 & 0.008 \\
\hline
\end{tabular}

TBARS values were expressed as mg MDA/kg of sample; ABTS values were expressed as mmol of Trolox equivalent/kg of sample; DPPH values were expressed as mmol of Trolox equivalent/10 kg of sample; FRAP values were expressed as mmol of Fe" equivalent per kg of meat.

$\mathrm{a}, \mathrm{b}, \mathrm{c}$ in the same row indicate significant differences for $\mathrm{D}$; ${ }^{\mathrm{x}, \mathrm{y}, \mathrm{z} \text { in }}$ the same row indicate significant differences for $\mathrm{T}$.

fed $0.6 \%$ of tannins supplementation showed higher capacity to inactivate oxidant probes than control fed rabbits; diet with $0.3 \%$ of tannins induced an antioxidant capacity with values between the other two diets.
Considering storage time all the samples increased their lipid peroxidation along with a decrease of antioxidant capacity.

As for raw samples no significant interaction $D \times T$ was showed in cooked samples for TBARS, ABTS and DPPH quantification. Lipid 
peroxidation of cooked samples showed to be affected by both $D$ and T. Samples derived from 0.6 diet showed lower oxidation after cooking than samples of the other two diets. The overall evaluation of TBARS of function of $\mathrm{T}$ showed a continuous increase of oxidation. No differences were shown for antioxidant capacity as function of the D. Instead, T affected the capacity of the samples to inhibit oxidation, and the results of cooked samples reflect the results of raw ones.

Several research studies were conducted to quantify the effects of natural antioxidant compound in diet on animal products. Regarding the employment of tannins in rabbit diet, Dalle Zotte and Cossu (2009) reported that supplementation with $1 \%$ and $3 \%$ of tannin extract from red quebracho trees did not modified the lipid oxidation of rabbit longissimus dorsi, on the contrary, Liu et al. (2012, 2009) showed that chestnut tannins increased the capacity of the meat to resist to an induced oxidation (with $\mathrm{FeSO}_{4}-7 \mathrm{H}_{2} \mathrm{O}$ ). As we employed a mix of quebracho and chestnut tannins seems that the characteristics of chestnut tannins were maintained and played a role in the inhibition of lipid peroxidation.

Antioxidant capacity of both chestnut and quebracho tannins were largely reported (Barreira, Ferreira, Oliveira, \& Pereira, 2008; Moreira, Leitão, Gonçalves, Wigg, \& Leitão, 2005). Anyhow, in animal trial, few research studies reported an increase of antioxidant capacity of meat; Luciano et al. (2011) reported an overall improvement of antioxidant status of muscles of lamb fed with quebracho tannins at concentration of $8.96 \%$ on dry matter basis. Voljč, Levart, Žgur, and Salobir (2013) evaluated the effects of chestnut tannins alone and in combination with $\alpha$-tocopherol on oxidative stress in vivo and the oxidative stability of meat in broilers and highlighted a scarce activity of chestnut tannins in vivo and in vitro oxidative stresses and hypothesized a sparing or regenerating effect on $\alpha$-tocopherol.

Further activity in vivo of chestnut tannins was reported by Frankič and Salobir (2011) against oxidative stress induced by high PUFA $\omega 3$ intake in young pigs with antioxidant and antigenotoxic effects similar to vitamin $\mathrm{E}$.

\section{4 | CONCLUSIONS}

Supplementation of a mix of chestnut and quebracho tannins seems to not modify extremely the physical characteristics of rabbit meat, as only a reduction of yellowness was revealed. Supplementation of tannins mix did not modify fatty acids profile of rabbit meat, thus the natural chemica and nutritional characteristics of rabbit meat were maintained. Tannins improved the capacity of both raw and cooked samples to resist to lipid peroxidation, moreover, an increased antioxidant capacity was showed in raw samples. Supplementation with $0.6 \%$ of chestnut and quebracho tannins mix seems to be a potential dose to forficate rabbit meat against oxidation without inducing modifications to the other characteristics.

\section{ACKNOWLEDGMENTS}

Authors thank Silvateam (Ledoga S.r.l.) for supplying tannins mix. The research was funded by PRA (Progetti di Ricerca di Ateneo) number PRA_2017_43.

\section{ORCID}

Simone Mancini (iD https://orcid.org/0000-0001-8643-507X

\section{REFERENCES}

AMSA. (1995). Research guidelines for cookery, sensory evaluation and instrumental tenderness measurements of fresh meat. Chicago, Illinois, USA: National Live Stock and Meat Board.

AOAC. (1995). Official methods of analysis of AOAC International, 15th ed. Washington, DC: Association of Official Analytical Chemists.

Barreira, J. C. M., Ferreira, I. C. F. R., Oliveira, M. B. P. P., \& Pereira, J. A. (2008). Antioxidant activities of the extracts from chestnut flower, leaf, skins and fruit. Food Chemistry, 107, 1106-1113. https://doi. org/10.1016/J.FOODCHEM.2007.09.030

Blasco, A., \& Ouhayoun, J. (1996). Harmonization of criteria and terminology in rabbit meat research, Revised proposal. World Rabbit Science, 4, 93-99.

Blois, M. S. (1958). Antioxidant determinations by the use of a stable free radical. Nature, 181, 1199-1200. https://doi.org/10.1038/1811199a0

Christie, W. W. (1982). A simple procedure for rapid transmethylation of glycerolipids and cholesteryl esters. Journal of Lipid Research, 23, 1072-1075.

Chung, K. T., Wong, T. Y., Wei, C. I., Huang, Y. W., \& Lin, Y.(1998). Tannins and human health: A review. Critical Reviews in Food Science and Nutrition, 38, 421-464. https://doi.org/10.1080/10408699891274273

CIE. (1976). Official recommendations on uniform colour spaces, colour differences equations and metric colour terms. Paris, France: Commission Internationale de l'Eclairage.

Corino, C., Pastorelli, G., Pantaleo, L., Oriani, G., \& Salvatori, G. (1999). Improvement of color and lipid stability of rabbit meat by dietary supplementation with vitamin E. Meat Science, 52, 285-289. https:// doi.org/10.1016/S0309-1740(99)00004-2

Dal Bosco, A., Castellini, C., Martino, M., Mattioli, S., Marconi, O., Sileoni, V., ... Benincasa, P. (2015). The effect of dietary alfalfa and flax sprouts on rabbit meat antioxidant content, lipid oxidation and fatty acid composition. Meat Science, 106, 31-37. https://doi. org/10.1016/J.MEATSCI.2015.03.021

Dal Bosco, A., Gerencsér, Z., Szendro, Z., Mugnai, C., Cullere, M., Kovàcs, M., ... Dalle Zotte, A. (2014). Effect of dietary supplementation of Spirulina (Arthrospira platensis) and Thyme (Thymus vulgaris) on rabbit meat appearance, oxidative stability and fatty acid profile during retail display. Meat Science, 96, 114-119. https://doi.org/10.1016/j. meatsci.2013.06.021

Dalle Zotte, A., \& Cossu, M. (2009). Dietary inclusion of tannin extract from red quebracho trees (Schinopsis spp.) in the rabbit meat production. Italian Journal of Animal Science, 8, 784-786. https://doi. org/10.4081/ijas.2009.s2.784

Descalzo, A. M., Rossetti, L., Grigioni, G., Irurueta, M., Sancho, A. M., Carrete, J., \& Pensel, N. A. (2007). Antioxidant status and odour profile in fresh beef from pasture or grain-fed cattle. Meat Science, 75, 309-317. https://doi.org/10.1016/j.meatsci.2006.07.015

Folch, J., Lees, M., \& Sloane-Stanley, G. H. (1957). A simple method for the isolation and purification of total lipides from animal tissues. Journal of Biological Chemistry, 226, 497-509.

Food and Agriculture Organization of the United Nation (FAO). (2018). Food and agriculture data. Retrieved from: http://www.fao.org/ faostat/en/\#data/QL

Frankič, T., \& Salobir, J. (2011). In vivo antioxidant potential of Sweet chestnut (Castanea sativa Mill.) wood extract in young growing pigs exposed to n-3 PUFA-induced oxidative stress. Journal of the Science of Food and Agriculture, 91, 1432-1439. https://doi.org/10.1002/jsfa.4328

Gai, F., Gasco, L., Liu, H. W., Lussiana, C., Brugiapaglia, A., Masoero, G., \& Zoccarato, I. (2009). Effect of diet chestnut tannin supplementation 
on meat quality, fatty acid profile and lipid stability in broiler rabbits. Italian Journal of Animal Science, 8, 787-789. https://doi.org/10.4081/ ijas.2009.s2.787

ISO 14088:2012. (2012). Leather - Chemical tests - Quantitative analysis of tanning agents by filter method. London, UK: IULTCS - International Union of Leather Technologists and Chemists Societies.

Jung, S., Choe, J. H., Kim, B., Yun, H., Kruk, Z. A., \& Jo, C. (2010). Effect of dietary mixture of gallic acid and linoleic acid on antioxidative potential and quality of breast meat from broilers. Meat Science, 86 , 520-526. https://doi.org/10.1016/j.meatsci.2010.06.007

Karabagias, I., Badeka, A., \& Kontominas, M. G. (2011). Shelf life extension of lamb meat using thyme or oregano essential oils and modified atmosphere packaging. Meat Science, 88, 109-116. https://doi. org/10.1016/j.meatsci.2010.12.010

Leick, C. M., Puls, C. L., Ellis, M., Killefer, J., Carr, T. R., Scramlin, S. M., ... McKeith, F. K. (2010). Effect of distillers dried grains with solubles and ractopamine (Paylean) on quality and shelf-life of fresh pork and bacon. Journal of Animal Science, 88, 2751-2766. https://doi. org/10.2527/jas.2009-2472

Liu, H. W., Dong, X. F., Tong, J. M., \& Zhang, Q. (2011). A comparative study of growth performance and antioxidant status of rabbits when fed with or without chestnut tannins under high ambient temperature. Animal Feed Science and Technology, 164, 89-95. https://doi. org/10.1016/j.anifeedsci.2010.09.020

Liu, H., Gai, F., Gasco, L., Brugiapaglia, A., Lussiana, C., Guo, K. J., ... Zoccarato, I. (2009). Effects of chestnut tannins on carcass characteristics, meat quality, lipid oxidation and fatty acid composition of rabbits. Meat Science, 83, 678-683. https://doi.org/10.1016/j. meatsci.2009.08.003

Liu, H., Li, K., Mingbin, L., Zhao, J., \& Xiong, B. (2016). Effects of chestnut tannins on the meat quality, welfare, and antioxidant status of heat-stressed lambs. Meat Science, 116, 236-242. https://doi. org/10.1016/J.MEATSCI.2016.02.024

Liu, H., Zhou, D., Tong, J., \& Vaddella, V. (2012). Influence of chestnut tannins on welfare, carcass characteristics, meat quality, and lipid oxidation in rabbits under high ambient temperature. Meat Science, 90, 164-169. https://doi.org/10.1016/j.meatsci.2011.06.019

Lo Fiego, D., Santoro, P., Macchioni, P., Mazzoni, D., Piattoni, F., Tassone, F., \& De Leonibus, E. (2004). The effect of dietary supplementation of vitamins $C$ and $E$ on the $\alpha$-tocopherol content of muscles, liver and kidney, on the stability of lipids, and on certain meat quality parameters of the longissimus dorsi of rabbits. Meat Science, 67, 319-327. https://doi.org/10.1016/j.meatsci.2003.11.004

Luciano, G., Monahan, F. J., Vasta, V., Biondi, L., Lanza, M., Bella, M., ... Priolo, A. (2009). Lamb meat colour stability as affected by dietary tannins. Italian Journal of Animal Science, 8, 507-509. https://doi. org/10.1016/j.meatsci.2008.07.006

Luciano, G., Vasta, V., Monahan, F. J., López-Andrés, P., Biondi, L., Lanza, M., \& Priolo, A. (2011). Antioxidant status, colour stability and myoglobin resistance to oxidation of longissimus dorsi muscle from lambs fed a tannin-containing diet. Food Chemistry, 124, 1036-1042. https://doi.org/10.1016/J.FOODCHEM.2010.07.070

Lundström, K., \& Malmfors, G. (1985). Variation in light scattering and waterholding capacity along the porcine Longissimus dorsi muscle. Meat Science, 15, 203-214. https://doi.org/10.1016/0309-1740(85)90076-2

Mancini, S., Moruzzo, R., Minieri, S., Turchi, B., Cerri, D., Gatta, D., ... Paci, G. (2018). Dietary supplementation of quebracho and chestnut tannins mix in rabbit: Effects on live performances, digestibility, carcass traits, antioxidant status, faecal microbial load and economic value. Italian Journal of Animal Science. https://doi.org/10.1080/1828 051X.2018.1549514

Mancini, S., Preziuso, G., Dal Bosco, A., Roscini, V., Parisi, G., \& Paci, G. (2017). Modifications of fatty acids profile, lipid peroxidation and antioxidant capacity in raw and cooked rabbit burgers added with ginger. Meat Science, 133, 151-158. https://doi.org/10.1016/j.meatsci.2017.07.003
Mancini, S., Preziuso, G., Dal Bosco, A., Roscini, V., Szendrő, Z., Fratini, F., \& Paci, G. (2015). Effect of turmeric powder (Curcuma longa L.) and ascorbic acid on physical characteristics and oxidative status of fresh and stored rabbit burgers. Meat Science, 110, 93-100. https:// doi.org/10.1016/j.meatsci.2015.07.005

Mancini, S., Preziuso, G., Fratini, F., Torracca, B., Nuvoloni, R., Dal Bosco, A., \& Paci, G. (2017). Qualitative improvement of rabbit burgers using Zingiber officinale Roscoe powder. World Rabbit Science, 25, 367. https://doi.org/10.4995/wrs.2017.7656

Mancini, S., Preziuso, G., \& Paci, G. (2016). Effect of turmeric powder (Curcuma longa L.) and ascorbic acid on antioxidant capacity and oxidative status in rabbit burgers after cooking. World Rabbit Science, 24, 121-127. https://doi.org/10.4995/wrs.2016.4207

Mancini, S., Secci, G., Preziuso, G., Parisi, G., \& Paci, G. (2018). Ginger (Zingiber officinale Roscoe) powder as dietary supplementation in rabbit: Life performances, carcass characteristics and meat quality. Italian Journal of Animal Science, 17, 867-872. https://doi.org/10.108 0/1828051X.2018.1427007

Marín-Martinez, R., Veloz-García, R., Veloz-Rodríguez, R., GuzmánMaldonado, S. H., Loarca-Pina, G., Cardador-Martinez, A., ... Guevara-Gonzalez, R. G. (2009). Antimutagenic and antioxidant activities of quebracho phenolics (Schinopsis balansae) recovered from tannery wastewaters. Bioresource Technology, 100, 434-439. https:// doi.org/10.1016/J.BIORTECH.2008.05.029

Mattioli, S., Cardinali, R., Balzano, M., Pacetti, D., Castellini, C., Dal Bosco, A., \& Frega, N. G. (2017). Influence of dietary supplementation with prebiotic, oregano extract, and vitamin $\mathrm{E}$ on fatty acid profile and oxidative status of rabbit meat. Journal of Food Quality, 2017, 1-9. https://doi.org/10.1155/2017/3015120

Moreira, D. d. L., Leitão, S. G., Gonçalves, J. L. S., Wigg, M. D., \& Leitão, G. G. (2005). Antioxidant and antiviral properties of Pseudopiptadenia contorta (Leguminosae) and of quebracho (Schinopsis sp.) extracts. Química Nova, 28, 421-425. https://doi.org/10.1590/S0100-40422005000300011

Mueller-Harvey, I. (2006). Unravelling the conundrum of tannins in animal nutrition and health. Journal of the Science of Food and Agriculture, 86, 2010-2037. https://doi.org/10.1002/(ISSN)1097-0010

Parisi, F., Mancini, S., Mazzei, M., Forzan, M., Turchi, B., Perrucci, S., ... Paci, G. (2018). Effect of dietary supplementation of a mix of chestnut and quebracho tannins on intestinal morphology, bacterial load, Eimeria spp oocyst excretion and immune response after vaccination in rabbits. American Journal of Animal and Veterinary Sciences, 13, 94103. https://doi.org/10.3844/ajavsp.2018.94.103

Petracci, M., \& Cavani, C. (2013). Rabbit meat processing: Historical perspective to future directions. World Rabbit Science, 21, 217-226. https://doi.org/10.4995/wrs.2013.1329

R Core Team. (2015). R: A language and environment for statistical computing. Vienna, Austria: R Foundation for Statistical Computing. Retrieved from: http://www.r-project.org/

Ranucci, D., Beghelli, D., Trabalza-Marinucci, M., Branciari, R., Forte, C., Olivieri, O., ... Acuti, G. (2015). Dietary effects of a mix derived from oregano (Origanum vulgare L.) essential oil and sweet chestnut (Castanea sativa Mill.) wood extract on pig performance, oxidative status and pork quality traits. Meat Science, 100, 319-326. https:// doi.org/10.1016/j.meatsci.2014.09.149

Re, R., Pellegrini, N., Proteggente, A., Pannala, A., Yang, M., \& Rice-Evans, C. (1999). Antioxidant activity applying an improved ABTS radical cation decolorization assay. Free Radical Biology and Medicine, 26, 1231-1237. https://doi.org/10.1016/ S0891-5849(98)00315-3

Santos-Silva, J., Bessa, R. J., \& Santos-Silva, F. (2002). Effect of genotype, feeding system and slaughter weight on the quality of light lambs: II. Fatty acid composition of meat. Livestock Production Science, 77, 187-194. https://doi.org/10.1016/S0301-6226(02)00059-3

Sharma, G., \& Bala, R. (2002). Digital color imaging handbook. London, UK: CRC Press. https://doi.org/10.1201/CRCEEASPROCE 
Smulikowska, S., Pastuszewska, B., Święch, E., Ochtabińska, A., Mieczkowska, A., Nguyen, V., \& Buraczewska, L. (2001). Tannin content affects negatively nutritive value of pea for monogastrics. Journal of Animal and Feed Sciences, 10, 511-523. https://doi.org/10.22358/ jafs/68004/2001

Ulbricht, T. L., \& Southgate, D. A. (1991). Coronary heart disease: Seven dietary factors. Lancet, 338, 985-992. https://doi. org/10.1016/0140-6736(91)91846-M

Van Buren, J. P., \& Robinson, W. B. (1969). Formation of complexes between protein and tannic acid. Journal of Agricultural and Food Chemistry, 17, 772-777. https://doi.org/10.1021/jf60164a003

Voljč, M., Levart, A., Žgur, S., \& Salobir, J. (2013). The effect of $\alpha$ -tocopherol, sweet chestnut wood extract and their combination on oxidative stress in vivo and the oxidative stability of meat in broilers. British Poultry Science, 54, 144-156. https://doi.org/10.1080/00071 668.2012.760190

How to cite this article: Mancini S, Minieri S, Buccioni A, Marzoni Fecia di Cossato M, Russo C, Paci G. The influence of dietary chestnut and quebracho tannins mix on rabbit meat quality. Anim Sci J. 2019;90:680-689. https://doi.org/10.1111/ asj.13194 